Int. J. Plant Sci. 177(5):419-431. 2016.

(C) 2016 by The University of Chicago. All rights reserved.

1058-5893/2016/17705-0004\$15.00 DOI: $10.1086 / 684748$

\title{
IDENTIFICATION OF DIFFERENTIALLY EXPRESSED GENES DURING LACE PLANT LEAF DEVELOPMENT
}

\author{
Gaolathe Rantong, ${ }^{1, *}$ Katrien Van Der Kelen, + Frank Van Breusegem, † and Arunika H. L. A. N. Gunawardena ${ }^{2, *}$ \\ *Department of Biology, Dalhousie University, 1355 Oxford Street, Life Sciences Centre, Halifax, Nova Scotia B3H 4R2, Canada; and \\ tDepartment of Plant Biotechnology and Bioinformatics, Ghent University, Vlaams Instituut voor Biotechnologie Department \\ of Plant Systems Biology, Technologiepark 927, B-9052 Ghent, Belgium
}

Editor: John L. Bowman

Premise of research. The lace plant is an excellent and unique model for studying developmentally regulated programmed cell death (PCD) in plants. Perforations form in highly predictable and easily accessible and distinguishable areas in lace plant leaves. However, little is known about the genes involved in regulation of this PCD or leaf development. In this study, for the first time, a general gene expression profile for lace plant leaf development was investigated.

Methodology. A cDNA-amplified fragment length polymorphism involving 64 primer combinations was used for a half-genome analysis of 4666 transcripts. Two hundred and thirty differentially expressed transcriptderived fragments (TDFs) were sequenced. A partial expressed sequence tag (EST) database for window-stage (in which PCD is occurring) leaves was also established. Through a reverse transcription polymerase chain reaction, the possible role of ubiquitin in lace plant PCD was investigated.

Pivotal results. Seventy-nine TDFs were successfully annotated. The isolated TDFs and ESTs encoded genes involved in processes such as photosynthesis, biosynthesis pathways, gene regulation, stress responses, defense against pathogens, and PCD, among others. Indirect evidence through ubiquitin transcript levels suggests involvement of proteasome machinery in lace plant development and PCD. This study provides a foundation for selective studies on regulation of lace plant leaf development and PCD.

Keywords: cDNA-amplified fragment length polymorphism, expressed sequence tags, lace plant, leaf development, perforation formation, programmed cell death.

\section{Introduction}

\section{Programmed Cell Death}

Programmed cell death (PCD) is essential for the response to stress and for adaptation, survival, and development in eukaryotes. PCD is genetically regulated and common in all forms of multicellular organisms (Lam 2004; Gadjev et al. 2008). PCD is involved throughout plant life-from death of the embryonic suspensor to death of the entire plant (Thomas and Franklin-Tong 2004; Gadjev et al. 2008). Plant PCD can be divided into two broad categories: environmentally induced and developmentally regulated (Gunawardena et al. 2004; Gunawardena 2008; reviewed in Rantong and Gunawardena 2015). Environmentally induced PCD is employed in response to salt stress, drought (Hameed et al. 2013), pathogens (Coll et al. 2014), ultraviolet light (Nawkar et al. 2013), heat (Lord and

\footnotetext{
1 Current address: Botswana International University of Science and Technology, Department of Biological and Biotechnological Sciences, College of Sciences, Private Bag 16, Palapye, Botswana.

2 Author for correspondence; e-mail: arunika.gunawardena@dal.ca.

Manuscript received September 2015; revised manuscript received October 2015; electronically published April 1, 2016.
}

Gunawardena 2011), and other external environmental cues. Developmentally regulated PCD is caused by intrinsic developmental cues and is involved in processes such as self-incompatibility in pollen (Thomas and Franklin-Tong 2004), embryonic suspensor deletion (Giuliani et al. 2002; Rogers 2005), aerenchyma formation (Gunawardena et al. 2001; Evans 2003), root cap shedding (Fendrych et al. 2014), leaf senescence (Lee and Chen 2002), and leaf remodeling in the lace plant (Gunawardena et al. 2004) and Monstera (Gunawardena et al. 2005).

\section{The Lace Plant}

The lace plant (fig. 1A) is an aquatic monocot endemic to Madagascar. It is a member of the family Aponogetonaceae. It is unique because it is one of the few known plant species that employ PCD to form perforations during normal leaf development. The only other known plants that utilize PCD for perforation formation are the Monstera species in the family Araceae (Gunawardena et al. 2005). In both of these plant species, perforations form through developmentally regulated PCD (Gunawardena and Dengler 2006). However, unlike in Monstera, perforation formation in the lace plant is highly predictable. The perforations form in highly predictable areas, between longitudinal and transverse veins (fig. $1 B-1 E$ ). Perforation sites are 


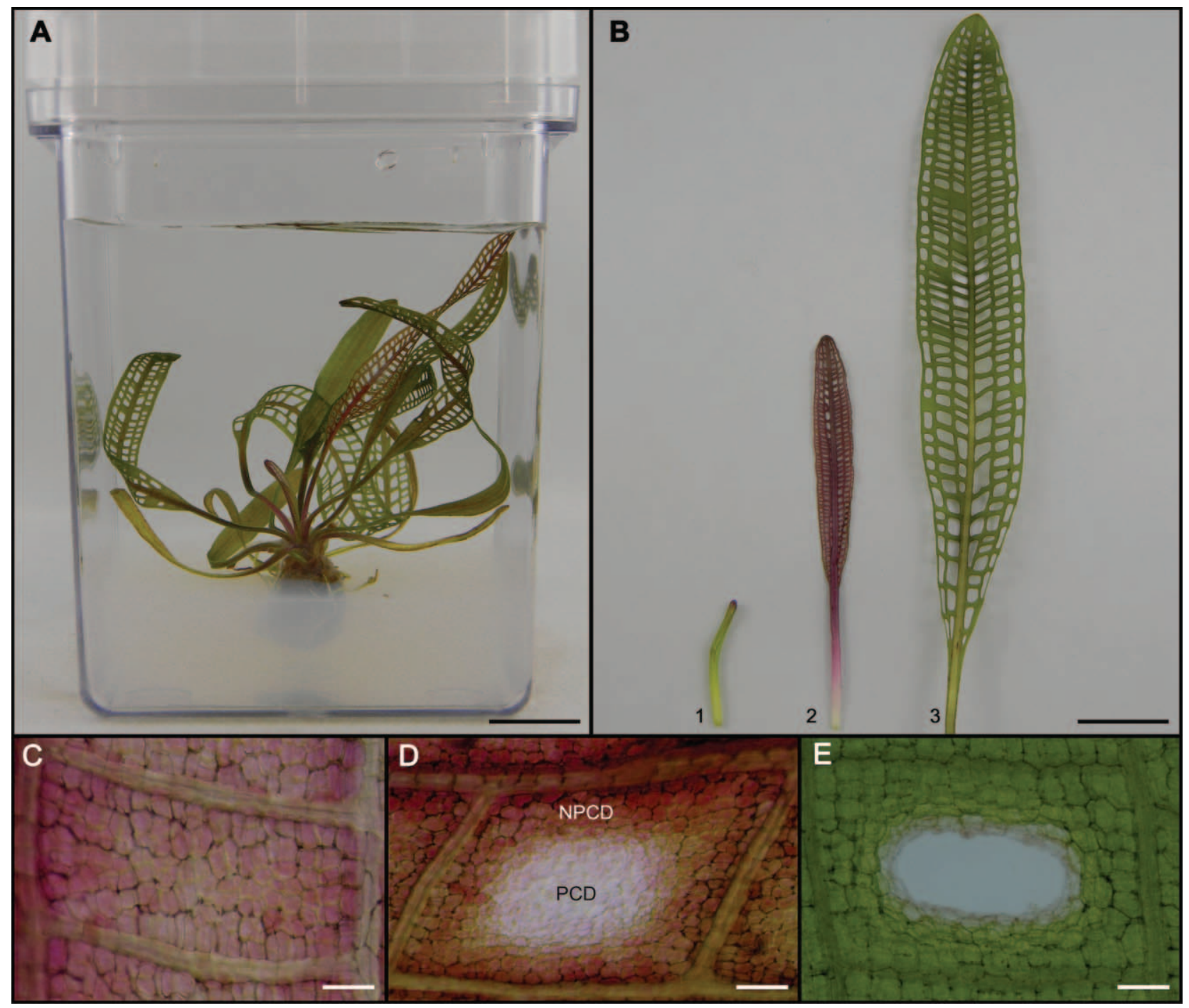

Fig. 1 Propagation of the lace plant and leaf development. $A$, Whole lace plant. The lace plants used in experiments in this study were grown in Magenta boxes under sterile conditions. The leaves emerge from a corm, and perforations form through developmentally regulated programmed cell death (PCD) to result in lace-like mature leaves. $B$, Three lace plant leaf developmental stages with different stages of perforation formation. In the preperforation stage (1), leaves have just emerged from the corm, and there are no obvious signs of perforation formation or PCD. Windowstage leaves (2) are pink due to anthocyanin, and PCD is occurring at the perforation site. In mature-stage leaves (3), perforations are complete, and there is no PCD occurring. $C$, An areole in a preperforation-stage leaf; all the cells look pink, and there is no sign of PCD or perforation formation. $D$, Within an areole in a window-stage leaf, cells at the center of the areole (PCD) lose their pigmentation and undergo PCD. The rest of the cells (NPCD), about four or five cell layers away from the vascular tissue, remain intact and alive. $E$, In mature-stage leaf areoles, PCD has stopped four or five cell layers away from vasculature, and all the cells are green. Scale bars: $A=1.25 \mathrm{~cm}, B=1 \mathrm{~cm}, C=150 \mu \mathrm{m}, D=360 \mu \mathrm{m}, E=500 \mu \mathrm{m}$.

easily visible, and perforations form during a specific stage of leaf development (window stage; fig. $1 B, 1 D$ ). Lace plant leaves are also almost transparent, a favorable characteristic for microscopy. Plants can be easily propagated through sterile cultures in Magenta boxes (fig. 1A) to provide microbe-free experimental tissue. These characteristics make the lace plant a good model for studying developmentally regulated PCD in plants (Dauphinee and Gunawardena 2015).

The process of perforation formation and the morphological aspects of PCD in the lace plant have been well studied (Gunawardena et al. 2004, 2006, 2007; Gunawardena and Dengler 2006; Gunawardena 2008; Wright et al. 2009; Elliott and
Gunawardena 2010; Wertman et al. 2012; Lord et al. 2013; Dauphinee et al. 2014). Gunawardena et al. (2004) divided and characterized the formation of perforations in lace plant leaves into five stages based on morphological characteristics. The preperforation stage (stage 1) occurs immediately following leaf emergence from the corm as it begins to unfurl. At this stage, the vascular tissue is well developed, displaying a grid-like pattern over the surface of the leaf; no signs of PCD are present at this point (fig. 1C). The window stage (stage 2) begins when leaves display the loss of pigments, such as chlorophyll and anthocyanin, in distinct areas (perforation sites) between transverse and longitudinal veins. These areas become almost transparent in 
comparison to the cells not undergoing PCD (four or five cell layers from the vascular tissue), which remain intact and retain their pigments. In the perforation-formation stage (stage 3), cells at the center of the perforation site begin to separate from adjacent cells, and a small hole forms through the leaf blade. During perforation expansion (stage 4), the perforations become larger as the leaf expands, and more cells die at the perforation site. In a mature leaf (stage 5), perforations are fully developed, and cells at the perforation border have transdifferentiated to become epidermal cells (Gunawardena et al. 2004). For this research, three stages of lace plant leaf development were used. Stage 1 was the preperforation stage, in which leaves did not display any obvious signs of PCD (fig. $1 B, 1 E$ ). Stage 2 was the window stage, where PCD is actively taking place at the perforation site (fig. $1 B, 1 D$ ). Stage 3 was the mature stage, where perforations were complete and no PCD was taking place (fig. $1 B, 1 E$ ).

Morphological cellular changes that occur in cells undergoing PCD in the lace plant have been well documented. These changes occur in a time period of about $48 \mathrm{~h}$ and include a decrease in the size of chloroplasts and starch grains, fluctuations in the number of transvacuolar strands, aggregation of chloroplasts around the nucleus, formation of conglomerates of organelles within the vacuole, swelling of the vacuole, a decrease in the size of the nucleus, changes in the actin filaments' architecture, loss of mitochondrial membrane potential, cessation of mitochondrial streaming, tonoplast rupture, and collapse of the plasma membrane (Wright et al. 2009; Wertman et al. 2012; Lord et al. 2013). All of the above-mentioned cellular changes take place in the cells undergoing PCD (PCD cells; fig. 1D) during perforation formation. Cells four or five layers from vascular tissue, which do not undergo PCD at this stage of leaf development (NPCD cells; fig. 1D), retain normal morphological cellular characteristics.

Even though the cellular changes that occur during PCD in lace plant leaf development are well studied, little is known about the genes involved in regulation of PCD during perforation formation (Rantong et al. 2015). The genomic sequence of the lace plant is also unknown; therefore, cDNA-amplified fragment length polymorphism (cDNA-AFLP) and expressed sequence tag (EST) database approaches were employed in this study. The cDNA-AFLP approach was used to provide a gene expression profile and elucidate genes that show differential expression during different stages of leaf development. It is a useful tool for future molecular studies, which will be focused more on studying genes involved in lace plant PCD. In addition, an EST database was created for window-stage leaves, during which PCD is occurring, to identify some of the genes expressed during this leaf developmental stage. The transcript expression pattern of ubiquitin throughout lace plant leaf development was also studied through a quantitative polymerase chain reaction (qPCR) to provide insights into the involvement of the proteasome-ubiquitin protein degradation pathway in lace plant PCD and leaf development.

\section{Material and Methods}

\section{Plant Propagation}

The lace plants were grown as described by Gunawardena et al. (2006) - in sterile conditions within Magenta boxes. They were grown under daylight-simulating fluorescent bulbs (Daylight Deluxe, F40T12/DX; Philips, Markham, Ontario), which provided approximately $125 \mu \mathrm{mol} \mathrm{m}{ }^{-2} \mathrm{~s}^{-1}$ of $12 \mathrm{~L}: 12 \mathrm{D}$ cycles. Leaves in the preperforation, window, mature, and senescence (only for qPCR reactions) stages were selected from these plants and used for RNA extraction.

\section{RNA Extraction}

Approximately $200 \mathrm{mg}$ of leaf tissue was used for each RNA extraction. The midrib was removed from the leaf tissue. RNA extraction was carried out according to the TRI reagent (SigmaAldrich, Oakville, Ontario) method, with some modifications. The modifications included elimination of air-drying the RNA pellet, using double the recommended volume of the TRI reagent, and maintaining the samples at a low temperature throughout RNA extraction.

\section{cDNA-AFLP Technique}

A cDNA-AFLP was carried out and processed essentially as described by Vuylsteke et al. (2007). First, 64 AFLP primer combinations with three selective nucleotides (BT1, BT2, BT3, and BT4, each in combination with Mse11, Mse12, Mse13, Mse14, Mse21, Mse22, Mse23, Mse24, Mse31, Mse32, Mse33, Mse34, Mse41, Mse42, Mse43, and Mse44) were used for selective amplification. The obtained fragments were separated on polyacrylamide gels. Gels were dried on blotting paper to enable the isolation of fragments from gels. For each primer combination, 50-100 transcript fragments were detectable, varying in length from 100 to $1000 \mathrm{bp}$. AFLP-QuantarPRO software (Keygene, Wageningen, Netherlands) was used to quantify band intensities in different lanes; oblique lanes were corrected, and unique transcript fragments were quantified, resulting in individual intensities for each time point per transcript fragment. Data were further corrected by doing a total lane correction. The residuals from these data normalizations were subjected to a one-factor ANOVA using the TIGR MultiExperiment Viewer of the TM4 software suite (Saeed et al. 2003). Genes with $P$ values of $<0.001$ were retained for further analysis. The expression values of selected fragments were median centered across each gene and again $\log 2$ transformed. The resulting data sets were subjected to hierarchical average linkage clustering (with a Euclidian distance metric) with the MultiExperiment Viewer of TM4 (Saeed et al. 2003). For each identified subcluster, the median-centered expression value for each replica was graphically presented ( $\log 2$ values). After data analysis, differentially expressed fragments were cut from gel and placed in $\mathrm{T}_{10} \mathrm{E}_{0.1}$ buffer for elution. These fragments were PCR amplified and directly sequenced.

\section{Construction of cDNA Library and EST Sequencing}

Window-stage leaves were used for the cDNA library, and total RNA from these leaves was extracted as described above. Spectrophotometry (ratio A260/280) and gel electrophoresis were used to verify the quality of the RNA. First-strand cDNA synthesis was carried out using the M-MuLV reverse transcriptase (200 U/ $\mu \mathrm{L}$; New England Biolabs, Pickering, Ontario), dT primer 5'-T18MN-3' (Integrated DNA Technology, Coralville, 
IA), dNTP mix (New England Biolabs), 5X First Strand Buffer (Invitrogen, Burlington, Ontario), RNase inhibitor $(40 \mathrm{U} / \mu \mathrm{L}$; New England Biolabs), and 0.1 M DTT (Invitrogen). Doublestranded cDNA was synthesized using DNA polymerase 1 (10 U/ $\mu \mathrm{L}$; Fermentas, Burlington, Ontario), dNTP mix and random hexamers (NNNNNN; Integrated DNA Technology), T4 DNA polymerase $(5000 \mathrm{U} / \mathrm{mL}$; Fermentas), and 0.5 M EDTA ( $\mathrm{pH} 8$; Fermentas). The blunt-ended, double-stranded DNA was then purified by phenol/chloroform extraction. The dsDNA was ligated into pUC19 DNA/SmaI Digested and Dephosphorylated (Fermentas) using T4 DNA Ligase (5 U/ $\mu \mathrm{L}$; Fermentas). Once transformed into Escherichia coli DH5 $\alpha$ (Invitrogen) competent cells, clones were manually picked, and plasmids were extracted using the GenElute plasmid miniprep kit (Sigma-Aldrich). The plasmids with inserts were sent to Macrogen (Rockville, MD) for sequencing. Sequences were edited using the BioEdit Sequence Alignment Editor (Carlsbad, Ottawa, Ontario) to trim low-quality and vector portions. Sequence annotation was performed by comparing insert sequences with nonredundant protein (blastx) and nucleotide (blastn) sequence databases at the National Center for Biotechnology Information (NCBI).

\section{$q P C R$}

For transcript level analysis, in addition to the three stages of leaf development described above, the senescence stage was also used. The Protoscript M-MuLV First Strand cDNA Synthesis Kit (New England Biolabs) was used for cDNA synthesis, according to manufacturer's instructions. The QuantiTect SYBR Green PCR Kit (Qiagen, Mississauga, Ontario) was used for qPCR in $20-\mu \mathrm{L}$ reactions using a Rotor-Gene 2000 (Qiagen) and following the manufacturer's instructions. Ubiquitin primers used in qPCR were 5'-GCCCTCACTGGAAAGACCATTACCC-3' and 5'-TCCCGCAAAAATCAGCCTCTGC-3'. Actin was used as a reference gene, and actin qPCR primers used were 5'-TACGACAGGTATCGTGCTTG- ${ }^{\prime}$ ' and $5^{\prime}$-CAAGCACGATACCTGTCGTA- ${ }^{\prime}$. The PCR product was verified through ligation into a $\mathrm{PGEM}-\mathrm{T}$ vector, cloned, and sequenced. qPCR conditions used were initial denaturing at $95^{\circ} \mathrm{C}$ for $15 \mathrm{~min}, 40$ cycles of denaturing at $94^{\circ} \mathrm{C}$ for $20 \mathrm{~s}$, primer annealing at $60^{\circ} \mathrm{C}$ for $20 \mathrm{~s}$, and elongation at $72^{\circ} \mathrm{C}$ for $30 \mathrm{~s}$. The melting curve was observed to determine purity of the PCR product. mRNA absolute copy numbers were determined through standard curves, which were generated as explained by Bustin et al. (2005). Ubiquitin absolute mRNA copy numbers were divided by actin mRNA copy numbers to generate mean normalized expression values.

\section{Statistical Analysis}

GraphPad Prism, version 5.00 (San Diego, CA), was used to analyze qPCR data. To determine significant differences in transcript levels, a general linear model of variance was used. After determining significance in the overall relationship, a Tukey post hoc test was used to compare means of individual treatments. Data were determined to be statistically significant if $P<0.05$. Data were collected from 16 independent RNA samples (four RNA samples of each leaf developmental stage). Tissue from at least three different leaves was used for each RNA sample.

\section{Results}

\section{Sequence Analysis of Transcript-Derived Fragments}

To assess differential gene expression throughout lace plant leaf development, three leaf developmental stages of lace plant perforation formation were selected. These are the preperforation, window, and mature stages (fig. $1 B$ ). Through cDNAAFLP analysis, transcript levels of 4666 transcripts were monitored throughout the three stages of leaf development. Figure 2 shows a section of a typical cDNA-AFLP gel that was run during this analysis. Most of the monitored transcripts displayed similar levels of expression, but those that showed differential expression were selected for further analysis. ANOVA analysis $(P<0.001)$ identified a total of 186 differentially expressed transcripts, of which 168 were isolated from the gels. Visual analysis resulted in an additional 62 fragments that displayed differential expression between the leaf developmental stages. A total of 230 fragments were isolated, reamplified, and sequenced.

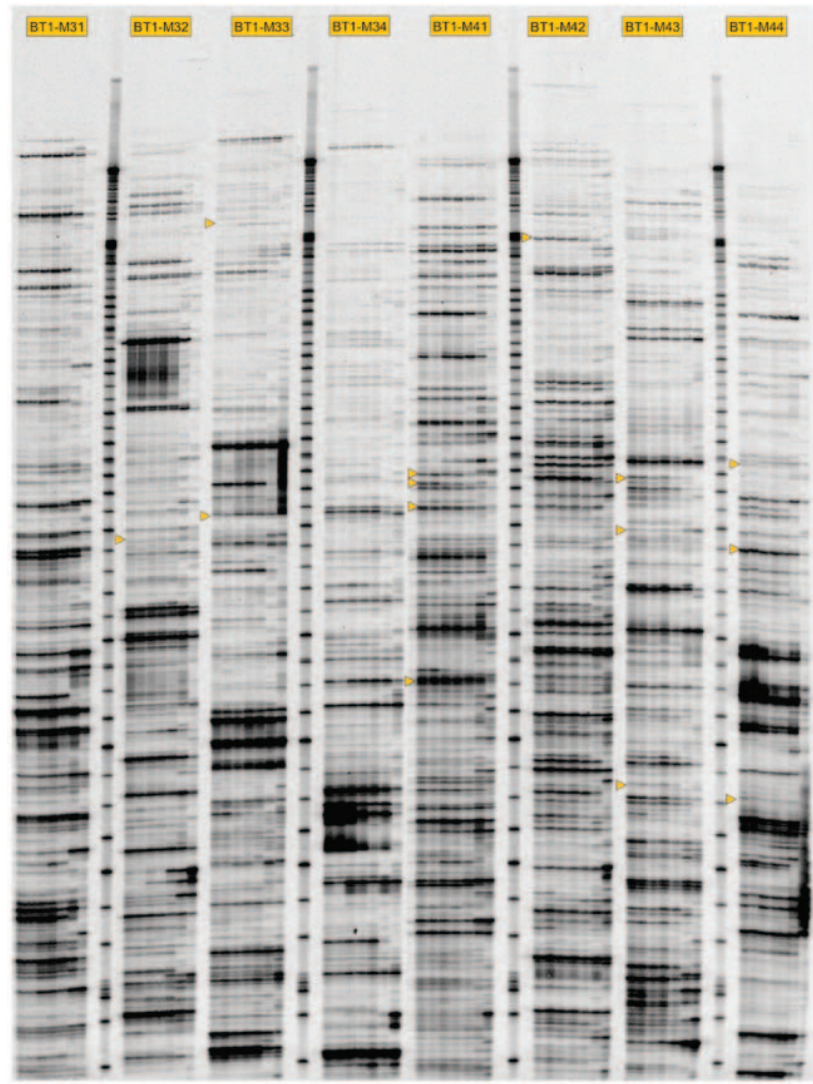

Fig. 2 cDNA-amplified fragment length polymorphism (cDNAAFLP) gel displaying differentially expressed transcript-derived fragments (TDFs). One of the cDNA-AFLP gels displays the pattern TDFs amplified by BT1-Mse31, BT1-Mse32, BT1-Mse33, BT1-Mse34, BT1Mse41, BT1-Mse42, BT1-Mse43, and BT1-Mse44. Lanes represent different samples from preperforation (lanes 1 and 2), window (lanes 3 and 4), mature (lanes 5 and 6), and senescent (lane 7) stages. Differentially expressed TDFs are highlighted by arrowheads. Note that the senescence stage had only one successfully analyzed sample (lane 7); therefore, due to lack of sufficient replicates, this leaf developmental stage was omitted from data analysis. 
The median-centered expression values for these fragments were calculated and used to produce a hierarchical clustering (fig. 3). Out of the 230 sequenced transcript-derived fragments (TDFs), 77 were successfully functionally annotated through alignments in the NCBI databases (table 1). Some of the TDFs were representatives of the same or similar genes. For example, TDF45, TDF91, TDF117, TDF160, and TDF231 encoded LRR receptor-like serine/threonine-protein kinases; TDF9 and TDF10 encoded polyubiquitin; TDF44, TDF229, and TDF230 encoded chlorophyll $a / b$ binding proteins; and TDF34 and TDF35 encoded a cold-regulated 413 plasma membrane protein 2-like gene. Some of the TDFs (TDF19, TDF102, and TDF232) were significantly similar to uncharacterized proteins of unknown functions.

\section{Functional Annotation and Expression Analysis}

Hierarchical average linkage clustering grouped genes with similar expression patterns into 24 clusters (figs. 3, 4). Of the 24 clusters, TDFs in four (clusters 4, 6, 9, and 15) displayed increased expression from the preperforation stage to the window stage. The other TDF clusters showed a decrease in expression (clusters 2, 3, 13, 14, 16, 20, and 22), while the rest displayed no difference in expression between the two developmental stages. Gene clusters that showed increased expression from window stage to mature stage were clusters $1,5,7,8,9,10,15,16$, and 18. TDFs in clusters $11,14,20,21,22$, and 23 showed decreased expression levels from window stage to mature stage, while the rest of the subclusters did not show any significant differences. TDFs in clusters 12 and 24 showed higher expression in mature stage than in preperforation stage but did not show any significant difference in expression between mature and window stages. Only one gene cluster (cluster 2) displayed low TDF expression levels in the window stage, in comparison with both preperforation and mature stages. Clusters 6, 18, and 20 consisted of the highest number $(16,17$, and 15 , respectively) of TDFs, making up $20.9 \%$ of the total number of TDFs showing differential expression. Clusters 2 and 24 had the lowest number of TDFs, each composed of three and two TDFs, respectively. The rest of the gene clusters consisted of between six and 13 TDFs. Clusters 6, 18, and 20 consisted of TDFs encoding protein kinases (TDF45, TDF160, and TDF231), membrane proteins (TDF196 and TDF48), ribosomal proteins (TDF189, TDF186, and TDF182), proteins involved in biosynthetic pathways (TDF49, TDF54, and TDF185), ATP binding (TDF45), phosphatases (TDF42), components involved in ubiquitination (TDF50, TDF57, and TDF165), transcriptional regulators (TDF171), and chloroplastic proteins (TDF44, TDF46, and TDF183), among others. The smallest cluster was cluster 24 , which was made up of two TDFs (TDF229 and TDF230). Both of these TDFs encode chloroplastic proteins.

\section{Lace Plant Window-Stage Leaf EST Database}

Window-stage leaves were chosen for construction of an EST database since they represent one of the most important stages of perforation formation. PCD was occurring in these leaves; therefore, some PCD-associated genes were likely to be isolated. Also, these leaves contain both PCD and NPCD cells; therefore, genes both expressed and downregulated during PCD are represented in these leaves. Most of the genes associated with PCD should be expressed in the window-stage leaves. A total of 147 ESTs were successfully cloned and sequenced, $62 \%$ of

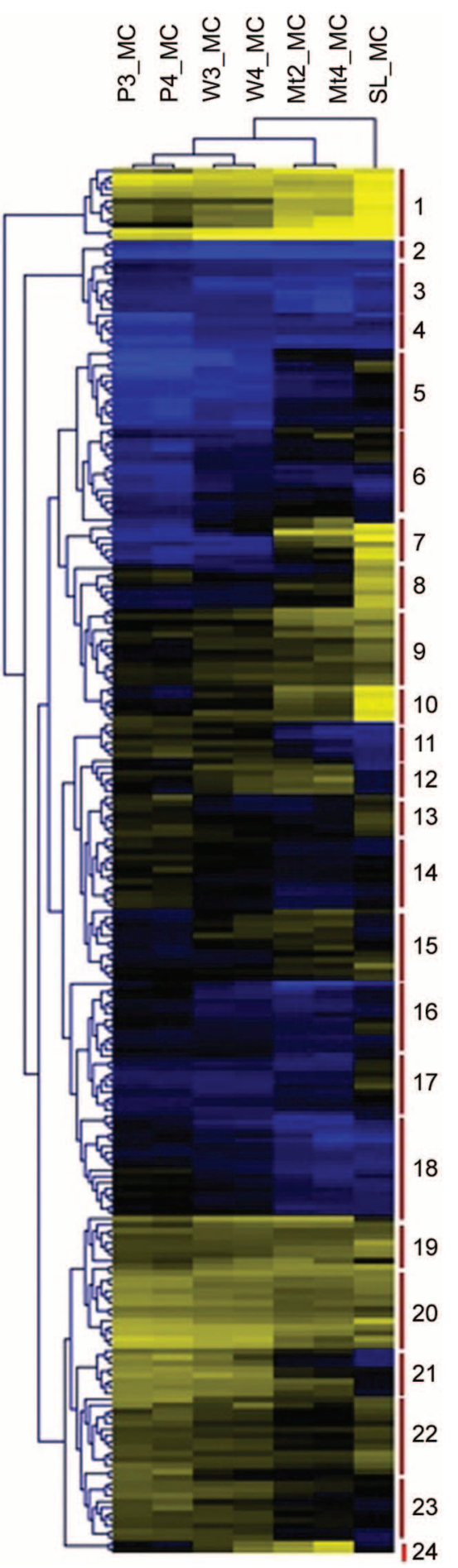

Fig. 3 Hierarchical clustering of differentially expressed transcriptderived fragments (TDFs). Hierarchical clustering of the median-centered normalized expression values of genes differentially expressed during the stages of lace plant leaf development is shown. Yellow indicates higher transcript levels, and blue indicates lower transcript levels. 
Table 1

Annotated Transcript-Derived Fragments (TDFs) Showing Differential Expression during the Three Stages of Lace Plant Leaf Development

\begin{tabular}{|c|c|c|c|c|c|}
\hline TDF & Primer combination & Length (bp) & Annotation & E-value & Accession no. \\
\hline TDF4 & bt3-m41 & 385 & RING/FYVE/PHD zinc finger superfamily protein & $5.00 \mathrm{E}-16$ & JZ845395 \\
\hline TDF9 & bt4-m32 & 268 & Ubiquitin & $6.00 \mathrm{E}-36$ & JZ845396 \\
\hline TDF10 & bt4-m32 & 256 & Ubiquitin & $5.00 \mathrm{E}-33$ & JZ845397 \\
\hline TDF19 & bt1-m33 & 321 & Lzipper-MIP1, SleB, and DUF547 domain-like protein & $4.00 \mathrm{E}-27$ & $\mathrm{JZ} 845400$ \\
\hline TDF20 & bt2-m14 & 603 & $60 S$ ribosomal protein L19 & $4.00 \mathrm{E}-45$ & JZ845401 \\
\hline TDF22 & bt3-m11 & 157 & Haloacid dehalogenase-like hydrolase domain-containing protein 3 & $8.00 \mathrm{E}-11$ & JZ845398 \\
\hline TDF23 & bt $3-\mathrm{m} 13$ & 225 & Glucan endo-1,3-beta-glucosidase 3 precursor & $7.00 \mathrm{E}-26$ & JZ845399 \\
\hline TDF26 & bt4-m23 & 433 & Histidinol dehydrogenase & $5.00 \mathrm{E}-32$ & $\mathrm{JZ} 845402$ \\
\hline TDF30 & bt1-m21 & 219 & Uridine kinase-like protein & $3.00 \mathrm{E}-24$ & JZ845403 \\
\hline TDF43 & bt2-m24 & 501 & YELLOW-LEAF-SPECIFIC GENE 9 (YLS9)-like & $7.00 \mathrm{E}-21$ & $\mathrm{JZ} 845404$ \\
\hline TDF42 & bt2-m42 & 346 & Probable protein phosphatase $2 \mathrm{C} 74$ & .046 & JZ845405 \\
\hline TDF36 & bt $3-\mathrm{m} 22$ & 150 & Thiamine thiazole synthase & $2.00 \mathrm{E}-23$ & JZ845406 \\
\hline TDF34 & bt3-m32 & 329 & Cold-regulated 413 plasma membrane protein 2 -like & $4.00 \mathrm{E}-35$ & $\mathrm{JZ} 845407$ \\
\hline TDF35 & bt3-m32 & 326 & Cold-regulated 413 plasma membrane protein 2 -like & $3.00 \mathrm{E}-44$ & $\mathrm{JZ} 845408$ \\
\hline TDF56 & bt3-m13 & 227 & ATP-binding cassette transporter & $7.00 \mathrm{E}-16$ & JZ845409 \\
\hline TDF45 & bt3-m13 & 368 & LRR receptor-like serine/threonine-protein kinase & .19 & $\mathrm{JZ} 845410$ \\
\hline TDF50 & bt3-m14 & 404 & F-box/kelch-repeat protein SKIP11-like & $5.00 \mathrm{E}-62$ & JZ845411 \\
\hline TDF46 & bt3-m21 & 467 & Protein CURVATURE THYLAKOID 1B & $5.00 \mathrm{E}-41$ & $\mathrm{JZ} 845412$ \\
\hline TDF57 & bt $3-\mathrm{m} 43$ & 203 & Hepatocyte growth factor-regulated tyrosine kinase substrate-like & $2.00 \mathrm{E}-05$ & $\mathrm{JZ} 845413$ \\
\hline TDF49 & bt $3-\mathrm{m} 43$ & 659 & Isopentenyl pyrophosphate isomerase & $3.00 \mathrm{E}-86$ & $\mathrm{JZ} 845414$ \\
\hline TDF44 & bt4-m11 & 498 & Light-harvesting complex II chlorophyll- $a / b$ binding protein & 4.00E-12 & $\mathrm{JZ} 845415$ \\
\hline TDF54 & bt1-m11 & 292 & Cinnamyl alcohol dehydrogenase & $3.00 \mathrm{E}-16$ & $\mathrm{JZ} 845416$ \\
\hline TDF48 & bt3-m34 & 410 & Mitochondrial chaperone BCS1-B & $1.00 \mathrm{E}-60$ & $\mathrm{JZ} 845417$ \\
\hline TDF60 & bt2-m42 & 193 & Peptidase M20/M25/M40 family-like protein & .8 & $\mathrm{JZ} 845418$ \\
\hline TDF77 & bt2-m13 & 127 & Nucleotidyltransferase/DNA polymerase & 2.0 & JZ845419 \\
\hline TDF81 & bt $2-\mathrm{m} 32$ & 499 & Calcium-binding protein CML24-like & .87 & $\mathrm{JZ} 845420$ \\
\hline TDF76 & bt $2-\mathrm{m} 43$ & 330 & 40 S ribosomal protein $\mathrm{S} 21$ & $6.00 \mathrm{E}-24$ & JZ845421 \\
\hline TDF74 & bt $3-\mathrm{m} 34$ & 476 & Glycosyl hydrolase & $2.00 \mathrm{E}-52$ & JZ845422 \\
\hline TDF90 & bt1-m33 & 212 & Allene oxide cyclase 4 & $2.00 \mathrm{E}-20$ & $\mathrm{JZ} 845423$ \\
\hline TDF91 & bt $2-\mathrm{m} 13$ & 100 & LRR receptor-like serine/threonine-protein kinase & $1.00 \mathrm{E}-04$ & $\mathrm{JZ} 845424$ \\
\hline TDF98 & bt1-m21 & 439 & High-mobility group B protein 6 -like & $6.00 \mathrm{E}-23$ & $\mathrm{JZ} 845425$ \\
\hline TDF93 & bt1-m42 & 433 & F-box-like/WD repeat-containing protein TBL1XR1 & $5.00 \mathrm{E}-41$ & $\mathrm{JZ} 845426$ \\
\hline TDF96 & bt2-m22 & 271 & High-mobility group B protein 7-like & $2.00 \mathrm{E}-26$ & JZ845427 \\
\hline TDF97 & bt2-m32 & 332 & Ubiquitin-conjugating enzyme E2 20-like & $3.00 \mathrm{E}-64$ & $\mathrm{JZ} 845428$ \\
\hline TDF103 & bt2-m21 & 161 & Synechocystis YCF37-like protein & .21 & JZ845429 \\
\hline TDF104 & bt $3-\mathrm{m} 14$ & 389 & Homogentisate phytyltransferase 1 , chloroplastic & $1.00 \mathrm{E}-22$ & JZ845431 \\
\hline TDF102 & bt3-m14 & 436 & Pentatricopeptide repeat (PPR) superfamily protein & $8.00 \mathrm{E}-16$ & JZ845431 \\
\hline TDF101 & bt3-m14 & 348 & Protein CURVATURE THYLAKOID 1B, chloroplastic & $6.00 \mathrm{E}-23$ & JZ845432 \\
\hline TDF100 & bt1m44 & 331 & Geranylgeranyl dehydrogenase & $3.00 \mathrm{E}-62$ & $\mathrm{JZ} 845433$ \\
\hline TDF105 & bt4-m12 & 76 & 50S ribosomal protein L15 & .014 & $\mathrm{JZ} 845434$ \\
\hline TDF117 & bt4-m11 & 147 & Leucine-rich repeat receptor-like serine/threonine-protein kinase BAM3 & $4.00 \mathrm{E}-14$ & $\mathrm{JZ} 845435$ \\
\hline TDF118 & bt4-m13 & 200 & SUN domain-containing protein 1 -like & $1.00 \mathrm{E}-11$ & $\mathrm{JZ} 845436$ \\
\hline TDF126 & bt2-m11 & 260 & Peptidyl-prolyl cis-trans isomerase CYP26-2, chloroplastic & $3.00 \mathrm{E}-26$ & JZ845437 \\
\hline TDF130 & bt2-m31 & 183 & Pentatricopeptide repeat-containing protein, chloroplastic & 7.2 & $\mathrm{JZ} 845438$ \\
\hline TDF124 & bt3-m14 & 304 & Integral membrane protein & $3.00 \mathrm{E}-22$ & JZ845439 \\
\hline TDF141 & bt2-m12 & 307 & Fructose-bisphosphate aldolase & $1.00 \mathrm{E}-49$ & $\mathrm{JZ} 845440$ \\
\hline TDF145 & bt3-m21 & 190 & Fatty acyl-CoA reductase 4 & $3.00 \mathrm{E}-25$ & JZ845441 \\
\hline TDF143 & bt4-m34 & 439 & Gamma-terpinene synthase & $1.00 \mathrm{E}-32$ & $\mathrm{JZ} 845442$ \\
\hline TDF138 & bt1-m12 & 75 & DNA/RNA-binding protein KIN17-like & $9.00 \mathrm{E}-05$ & $\mathrm{JZ} 845443$ \\
\hline TDF156 & bt2-m21 & 198 & Cytochrome P450 & 3.0 & $\mathrm{JZ} 845444$ \\
\hline TDF155 & bt $2-\mathrm{m} 33$ & 148 & Pentatricopeptide repeat-containing protein At4g33170-like & 3.2 & $\mathrm{JZ} 845445$ \\
\hline TDF165 & bt1-m43 & 285 & Ribosome biogenesis protein wdr12 & $2.00 \mathrm{E}-05$ & $\mathrm{JZ} 845446$ \\
\hline TDF172 & bt2-m24 & 148 & N-lysine methyltransferase-like protein & .008 & JZ845447 \\
\hline TDF231 & bt3-m11 & 365 & LRR receptor-like serine/threonine-protein kinase ERECTA & $2.00 \mathrm{E}-06$ & JZ845449 \\
\hline TDF160 & bt3-m11 & 399 & LRR receptor-like serine/threonine-protein kinase ERECTA & $3.00 \mathrm{E}-11$ & $\mathrm{JZ} 845450$ \\
\hline TDF163 & bt3-m14 & 241 & Auxin-responsive aux/iaa gene family member & $1.00 \mathrm{E}-16$ & $\mathrm{JZ} 845451$ \\
\hline TDF171 & bt3-m31 & 273 & Homeobox-leucine zipper protein HOX32 isoform X2 & $2.00 \mathrm{E}-05$ & $\mathrm{JZ} 845452$ \\
\hline TDF175 & bt3-m41 & 392 & 30 S ribosomal protein S5, chloroplastic-like & $1.00 \mathrm{E}-37$ & JZ845453 \\
\hline TDF196 & bt2-m32 & 164 & Alpha-tubulin & $7.00 \mathrm{E}-07$ & $\mathrm{JZ} 845455$ \\
\hline TDF191 & bt3-m12 & 168 & Relaxin-3 receptor & 7.0 & JZ845456 \\
\hline TDF186 & bt3-m41 & 200 & $60 S$ ribosomal protein L32-1-like & $7.00 \mathrm{E}-32$ & JZ845457 \\
\hline
\end{tabular}


Table 1 (Continued)

\begin{tabular}{|c|c|c|c|c|c|}
\hline TDF & Primer combination & Length (bp) & Annotation & E-value & Accession no. \\
\hline TDF185 & bt3-m42 & 151 & CDP-diacylglycerol-inositol 3-phosphatidyltransferase 2 & $1.00 \mathrm{E}-08$ & JZ845458 \\
\hline TDF183 & bt4-m11 & 82 & Translocase of chloroplast 34 & $5.00 \mathrm{E}-04$ & JZ845459 \\
\hline TDF182 & bt4-m41 & 300 & 50S ribosomal protein L17, chloroplastic-like & $1.00 \mathrm{E}-23$ & JZ845460 \\
\hline TDF200 & bt1-m44 & 195 & 50 S ribosomal protein L3-2, chloroplastic & $3.00 \mathrm{E}-16$ & JZ845461 \\
\hline TDF204 & bt2-m31 & 277 & FRIGIDA-like protein 3 & .56 & JZ845462 \\
\hline TDF197 & bt3-m12 & 108 & Transcriptional regulator & 1.6 & JZ845463 \\
\hline TDF203 & bt3-m44 & 201 & Remorin & $7.00 \mathrm{E}-04$ & JZ845464 \\
\hline TDF201 & bt3-m44 & 238 & Proliferating cell nuclear antigen & $1.00 \mathrm{E}-21$ & JZ845465 \\
\hline TDF206 & bt1-m12 & 116 & WUSCHEL-related homeobox 8-like protein & $3.00 \mathrm{E}-04$ & JZ845466 \\
\hline TDF209 & bt3-m14 & 210 & Beta-glucosidase & $1.00 \mathrm{E}-09$ & JZ845467 \\
\hline TDF214 & bt4-m22 & 72 & Galacturonosyltransferase & 1.2 & JZ845468 \\
\hline TDF219 & bt1-m23 & 184 & Protein LHCP TRANSLOCATION DEFECT-like & $1.00 \mathrm{E}-24$ & JZ845469 \\
\hline TDF232 & bt1-m41 & 217 & XP_001849016-like protein & .22 & JZ845470 \\
\hline TDF228 & bt3-m13 & 113 & Thionin & 8.95E-03 & JZ845471 \\
\hline TDF222 & bt3-m21 & 242 & Serine/arginine-rich splicing factor RS2Z32-like & .53 & JZ845472 \\
\hline TDF227 & bt4-m21 & 289 & U5 small nuclear ribonucleoprotein $40 \mathrm{kDa}$ protein & $3.00 \mathrm{E}-60$ & JZ845473 \\
\hline TDF229 & bt4-m31 & 509 & Light harvesting chlorophyll $a / b$ binding protein & $6.00 \mathrm{E}-71$ & JZ845474 \\
\hline TDF230 & bt4-m44 & 535 & Chlorophyll $a / b$ binding protein 6 , chloroplastic-like & $4.00 \mathrm{E}-73$ & JZ845475 \\
\hline TDF173 & bt2-m44 & 160 & Defensin-like protein & 3.1 & JZ845448 \\
\hline TDF189 & bt2-m44 & 111 & Phospho-N-acetylmuramoyl-pentapeptide-transferase-like & 3.00E-09 & JZ845454 \\
\hline
\end{tabular}

which were successfully annotated as identified (table 2) known proteins or uncharacterized proteins. The rest of the ESTs did not reveal homology within the GenBank database, using default parameters. Some ESTs, such as the putative senescence-associated protein (table 2), were isolated multiple times, suggesting that they are abundantly expressed in window-stage leaves.

\section{Studying Ubiquitin Transcript Levels through qPCR}

Several proteins involved in the ubiquitin-dependent protein degradation mechanism that involves the proteasome were isolated through both cDNA-AFLP (TDF9 and TDF10) and the EST database (EST3, EST121, and EST306). To determine the involvement of this mechanism in lace plant PCD and leaf development, ubiquitin transcript levels were investigated throughout leaf development through qPCR. In addition to the three leaf development stages discussed above, senescent-stage leaves were also included in transcript level analysis, since PCD is occurring in window- and senescent-stage leaves. Actin was used as a reference gene, and its transcript levels were constant throughout leaf development (fig. 5A). Ubiquitin transcript levels were significantly higher in senescence-stage leaves than in all the other developmental stages $(P<0.05)$. Window-stage leaves had significantly higher transcript levels than preperforationand mature-stage leaves $(P<0.05)$. There were no significant differences in ubiquitin transcript levels between preperforationand mature-stage leaves (fig. 5).

\section{Discussion}

Due to a lack of the known genome sequence, it has been challenging to study the genetic regulation of PCD and leaf development in the lace plant. The data accumulated through both cDNA-AFLP and the EST database provide a foundation to study the genetic regulation of PCD in the lace plant and other processes of interest. TDFs isolated through cDNA-AFLP encoded genes involved in processes such as translation, photosynthesis, gene regulation, stress responses, defense against pathogens, biosynthesis pathways, and PCD, among others. Table 3 lists the subclusters, their annotated TDFs, and the cellular processes the TDFs are involved in. Only one or none of the TDFs in subclusters 2, 7, and 8 was successfully annotated; therefore, these subclusters were not included in the table.

The TDFs potentially involved in PCD include polyubiquitin, ubiquitin-conjugating enzyme, YLS9, and LRR receptorlike serine/threonine-protein kinases (Bachmair et al. 1990; Woffenden et al. 1998; Heyndrickx et al. 2012; reviewed in Rantong and Gunawardena 2015). Ubiquitin is currently the most structurally conserved protein isolated. Its amino acid sequence is the same in all higher plants (Callis et al. 1995). Ubiquitin is involved in protein degradation in conjunction with the $26 \mathrm{~S}$ proteasome during several processes, including PCD (Bachmair et al. 1990; Woffenden et al. 1998). During senescence, the ubiquitin-dependent proteasome system is responsible for the tremendous protein turnover (Vierstra 1996). Transcript level analysis suggests that ubiquitin might be involved in protein turnover that occurs during perforation formation and senescence in the lace plant (fig. 5). The increased ubiquitin transcript levels during the leaf developmental stages where PCD is occurring (window and senescence) support the potential involvement of ubiquitin and the proteasome protein degradation mechanism in lace plant PCD. The ubiquitin-conjugating enzyme (TDF97) is also involved in the ubiquitin/26S proteasome system. It is part of a sequence of enzymes involved in the pathway that attaches ubiquitin molecules to target proteins (Vierstra 2009). YLS9 is involved in processes such as hypersensitive response, leaf senescence, and regulation of PCD (Zheng et al. 2004; Heyndrickx et al. 2012). The specific molecular mechanism through which YLS9 is involved in these processes is unknown. LRR receptor-like serine/threonine-protein kinases are involved in signalling during response to pathogen attack, 

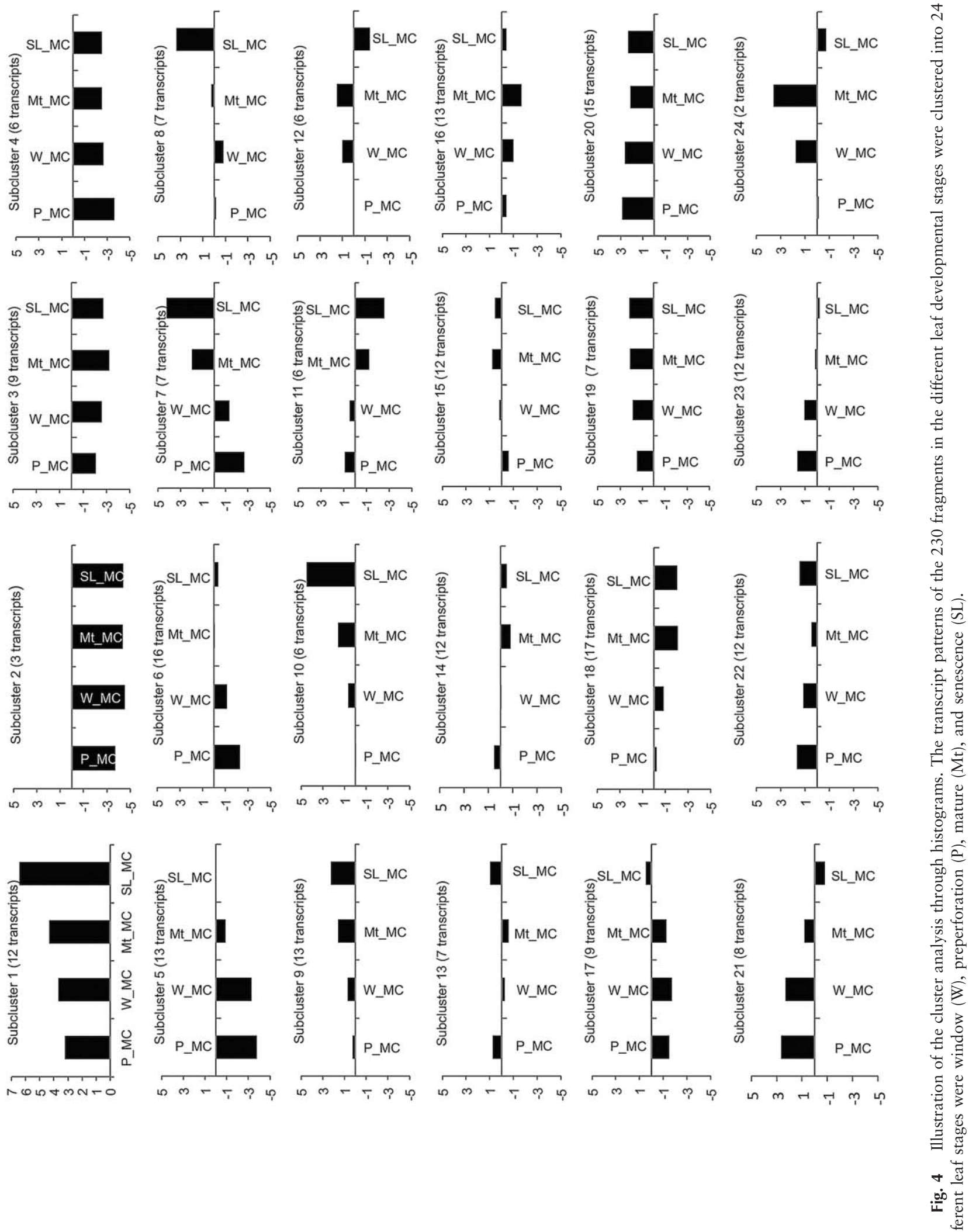
Table 2

Successfully Annotated Expressed Sequence Tags (ESTs) from Lace Plant Window-Stage Leaves

\begin{tabular}{|c|c|c|c|c|}
\hline EST & Length (bp) & Annotation & E-value & Accession no. \\
\hline 1 & 261 & Cytochrome P450 monooxygenase & $3.00 \mathrm{E}-60$ & $\ldots$ \\
\hline 3 & 428 & $20 S$ proteasome beta subunit PBG1 & $1.00 \mathrm{E}-33$ & JZ897089 \\
\hline 23 & 698 & GTP-binding protein SAR1A & $3.00 \mathrm{E}-72$ & JZ897090 \\
\hline 49 & 486 & $23 \mathrm{~S}$ ribosomal RNA & $2.00 \mathrm{E}-28$ & $\ldots$ \\
\hline 56 & 351 & $50 S$ ribosomal protein L22 & $9.00 \mathrm{E}-50$ & JZ897091 \\
\hline 505 & 744 & Chloroplast photosystem II $10 \mathrm{kDa}$ protein & $3.00 \mathrm{E}-37$ & JZ897092 \\
\hline 508 & 504 & Tankyrase 1 & $1.00 \mathrm{E}-27$ & JZ897093 \\
\hline 510 & 876 & Cytochrome P450 monooxygenase & $1.00 \mathrm{E}-38$ & $\ldots$ \\
\hline 512 & 116 & Chloroplast hypothetical protein & $2.00 \mathrm{E}-04$ & $\ldots$ \\
\hline 517 & 315 & $40 S$ ribosomal protein $\mathrm{S} 17$ & $2.00 \mathrm{E}-10$ & JZ897094 \\
\hline 522 & 150 & $60 S$ ribosomal protein L34 & $1.00 \mathrm{E}-25$ & JZ897095 \\
\hline 531 & 443 & Photosystem I reaction center subunit psaK & $2.00 \mathrm{E}-40$ & JZ897096 \\
\hline 536 & 591 & 40 S ribosomal protein $S 3 \mathrm{a}$ & $5.00 \mathrm{E}-135$ & JZ897097 \\
\hline 539 & 992 & rRNA intron-encoded homing endonuclease & 4.00E-61 & $\ldots$ \\
\hline 549 & 382 & Calmodulin-binding protein 1 & $9.00 \mathrm{E}-09$ & JZ897098 \\
\hline 551 & 367 & Retrotransposon protein & $1.00 \mathrm{E}-08$ & $\ldots$ \\
\hline 552 & 445 & Mitochondrial import receptor subunit TOM20 & 4.00E-06 & JZ897099 \\
\hline 439 & 583 & GTP-binding protein SAR1-like & $1.00 \mathrm{E}-65$ & JZ897100 \\
\hline 77 & 158 & WRKY24-like & $3.00 \mathrm{E}-04$ & $\mathrm{JZ} 897101$ \\
\hline 96 & 237 & WRKY transcription factor & $6.00 \mathrm{E}-07$ & JZ897102 \\
\hline 100 & 253 & WRKY-like & $8.00 \mathrm{E}-02$ & JZ897103 \\
\hline 384 & 962 & Oxygen-evolving enhancer protein 1 & $2.00 \mathrm{E}-170$ & JZ897122 \\
\hline 511 & 284 & $26 \mathrm{~S}$ large subunit ribosomal RNA gene & $1.00 \mathrm{E}-140$ & $\ldots$ \\
\hline 386 & 250 & $18 \mathrm{~S}$ small subunit ribosomal RNA gene & $1.00 \mathrm{E}-121$ & $\ldots$ \\
\hline 395 & 135 & 23S ribosomal RNA gene & $4.00 \mathrm{E}-43$ & $\ldots$ \\
\hline 155 & 418 & Cellulose synthase-like protein G3 & $9.00 \mathrm{E}-31$ & JZ897105 \\
\hline 491 & 260 & Putative senescence-associated protein & $8.00 \mathrm{E}-39$ & $\ldots$ \\
\hline 326 & 463 & Cell wall-associated hydrolase & $1.00 \mathrm{E}-53$ & $\ldots$ \\
\hline 403 & 171 & NADH dehydrogenase subunit 3 & $2.00 \mathrm{E}-06$ & JZ897114 \\
\hline 89 & 138 & UDP-glycosyltransferase & $5.00 \mathrm{E}-07$ & JZ897115 \\
\hline 13 & 492 & Thionin & $3.00 \mathrm{E}-07$ & JZ897116 \\
\hline 172 & 197 & Serine/threonine-protein kinase Nek2-like & $8.00 \mathrm{E}-03$ & JZ897112 \\
\hline 306 & 454 & EIN3-binding F-box protein 1-like & $7.00 \mathrm{E}-06$ & JZ897106 \\
\hline 151 & 713 & Leishmanolysin & $4.00 \mathrm{E}-126$ & JZ897107 \\
\hline 166 & 794 & Methylsterol monooxygenase 2-2-like & $4.00 \mathrm{E}-141$ & JZ897108 \\
\hline 113 & 493 & Chlorophyll $a / b$ binding protein & $2.00 \mathrm{E}-51$ & JZ897104 \\
\hline 114 & 864 & RNA-directed DNA polymerase (reverse transcriptase); ribonuclease $\mathrm{H}$ & $9.00 \mathrm{E}-73$ & JZ897109 \\
\hline 115 & 244 & Fructose-bisphosphate aldolase, class I & $8.00 \mathrm{E}-34$ & JZ897110 \\
\hline 116 & 168 & Transformation/transcription domain-associated protein & $9.00 \mathrm{E}-17$ & JZ897111 \\
\hline 118 & 564 & Putative retroelement & $1.00 \mathrm{E}-39$ & JZ897113 \\
\hline 119 & 962 & Oxygen-evolving enhancer protein 1 & $2.00 \mathrm{E}-170$ & JZ897117 \\
\hline 120 & 295 & 50 S ribosomal protein $\mathrm{L} 21$ & $7.00 \mathrm{E}-25$ & $\mathrm{JZ} 897118$ \\
\hline 121 & 345 & Ubiquitin-specific protease 14 & $1.00 \mathrm{E}-31$ & JZ897119 \\
\hline 122 & 610 & Cyclin-B2-2-like & $3.00 \mathrm{E}-60$ & $\mathrm{JZ} 897120$ \\
\hline 123 & 603 & f13j11 PRLI-interacting factor $G$ & $2.00 \mathrm{E}-65$ & JZ897121 \\
\hline
\end{tabular}

response to abiotic stresses, and PCD (Song et al. 1995; Oh et al. 2010; Park et al. 2014).

In addition to the TDFs involved in PCD, the EST database contains some of the genes known to be involved in different forms of PCD in other plant species. These include the $20 S$ proteasome beta subunit (EST3), EIN3-binding F-box protein 1 (EST306), a calmodulin-binding protein (EST549), a senescence-associated protein (EST491), WRKY transcription factors (EST77, EST96, and EST100), and cytochrome P450 monooxygenase (EST1 and EST510; also isolated through cDNA-AFLP). Other TDFs and ESTs isolated through both cDNA-AFLP and the EST database include thionin and chlorophyll $a / b$ binding proteins.
The 20 S proteasome $\beta$ subunit is involved in the ubiquitinproteasome-dependent regulated degradation of proteins (Baumeister et al. 1998; Kim et al. 2006). It is a part of the 26S proteasome, which recognizes and degrades ubiquitinated proteins. The $26 \mathrm{~S}$ proteasome is comprised of a $20 \mathrm{~S}$ core particle with $19 \mathrm{~S}$ regulatory particles attached to it. The $20 \mathrm{~S}$ proteasome consists of 28 subunits that are encoded by distinct but related genes (Baumeister et al. 1998). In eukaryotes, the subunits are divided into archaeal $\alpha$ or $\beta$ subunits; a $\beta$ subunit was isolated in this study. Several functions of the $20 \mathrm{~S}$ proteasome have been described in eukaryotes, the most significant being its involvement in ubiquitin-dependent proteolysis (Coux et al. 1996; Hoch- 

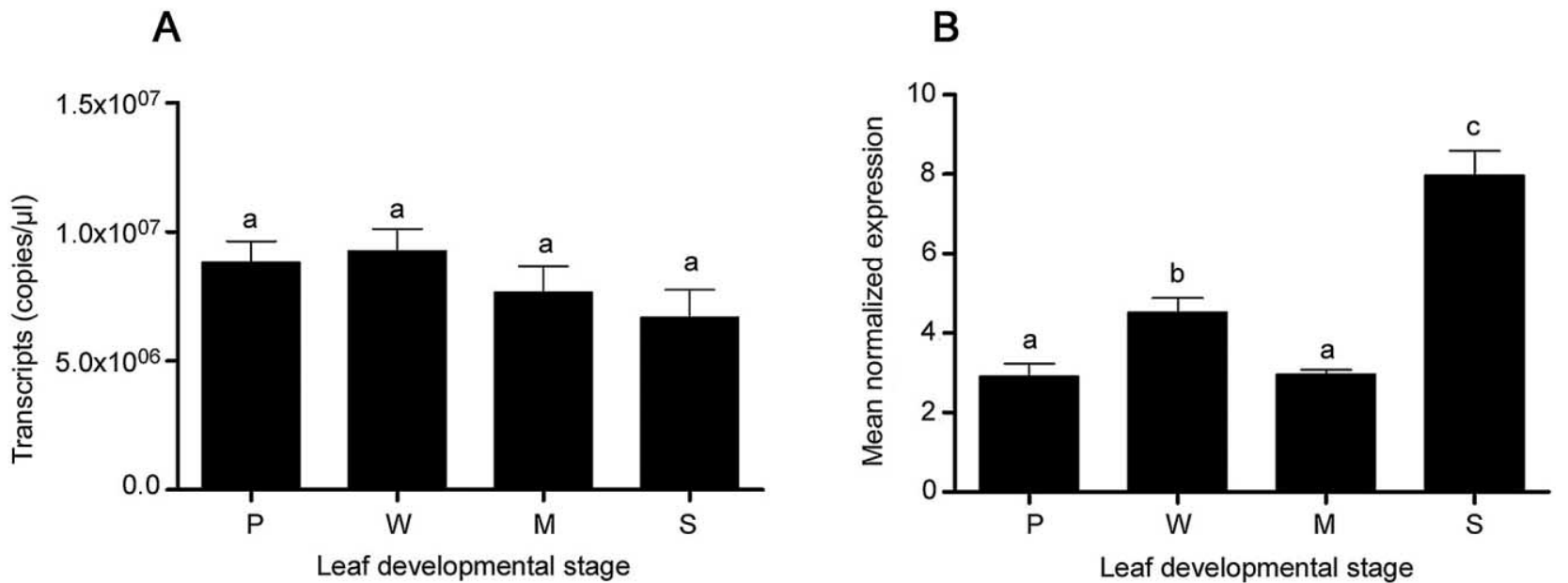

Fig. 5 Actin and ubiquitin transcript levels during different stages of leaf development. $A$, Actin transcript levels. Actin was used as a reference gene, and it had similar transcript levels throughout leaf development. $B$, Normalized ubiquitin transcript levels during the different stages of leaf development. There was no significant difference in ubiquitin transcript levels in preperforation- and mature-stage leaves. Window- and senescence-stage leaves had significantly higher transcript levels than preperforation- and mature-stage leaves. Senescence-stage leaves had more ubiquitin transcript levels than window-stage leaves. Bars represent SE $(n \geq 8)$. Means with the same letters are not significantly different $(P>$ $0.05) . \mathrm{M}=$ mature stage, $\mathrm{P}=$ preperforation stage, $\mathrm{S}=$ senescence stage, $\mathrm{W}=$ window stage.

strasser 1996; Vierstra 1996). It would be useful to determine its involvement in lace plant PCD and perforation formation as well as the role of the $26 \mathrm{~S}$ proteasome as a whole. This would provide insights into whether protein turnover and nutrient recycling occur during perforation formation in the lace plant. EIN3-binding F-box protein 1 is a ubiquitin protein ligase involved in ethylene-regulated PCD in plants (Gagne et al. 2004). It is a constituent of a protein complex $\left(\mathrm{SCF}^{\mathrm{EBF} 1 / 2}\right)$ that directs the targeting of EIN3 for degradation through a ubiquitin-dependent pathway involving the proteasome (Guo and Ecker 2003; Gagne et al. 2004). EIN3 is a transcription factor required for induction of gene expression regulated by ethylene, including during ethylene-dependent PCD (Chao et al. 1997; Alonso et al. 2003). PCD in the lace plant is ethylene dependent (Dauphinee et al. 2012; Rantong et al. 2015); therefore, it is likely that EIN3binding F-box protein 1 plays an important role in the regulation of lace plant PCD. Through orchestrating the degradation EIN3, EIN3-binding F-box protein 1 is also important for enhancing plant growth (Gagne et al. 2004).

Calmodulin-binding proteins such as AtBAG6 in Arabidopsis are known to be involved in PCD (Kang et al. 2006). AtBAG6 has a BCL-2-associated athanogene (BAG) domain, and when it is overexpressed, it can induce PCD. Calmodulinbinding protein 1 (EST 549) was isolated from the lace plant; however, it is unknown whether it is involved in lace plant PCD. Nevertheless, it is known that calcium signaling is essential in PCD during perforation formation in the lace plant (Elliott and Gunawardena 2010). Calmodulin-binding proteins are involved in a wide range of other processes, such as transcriptional regulation, phosphorylation, and metabolism (Snedden and Fromm 2001; Hoeflich and Ikura 2002).

Other clones of interest are the WRKY transcription factors. WRKY transcription factors are ubiquitous in plants and pos- sess highly conserved characteristic amino acid motifs, which contain the WRKYGQK sequences followed by Cys(2)-His(2) or Cys(2)-His-Cys zinc-binding motifs (Zhou et al. 2011). There are 74 members of this gene family in Arabidopsis and 109 in rice (Eulgem and Somssich 2007; Ross et al. 2007). They are believed to be involved in regulation of several physiological processes in plants, such as immunity (Pandey and Somssich 2009), embryogenesis (Lagacé and Matton 2004), hormonal signaling (Zhang et al. 2004; Xie et al. 2005), trichome and seed coat development (Johnson et al. 2002), regulation of biosynthesis pathways (Xu et al. 2004), and senescence (Lin and Wu 2004; Buchanan-Wollaston et al. 2005). WRKY transcription factors play a role in plant immunity by regulating the expression of defense response genes (Eulgem et al. 2000; Heise et al. 2002). Plant immunity and senescence involve PCD; therefore, the WRKY transcription factors likely play a role in PCD. It would be a significant step to determine the role of these transcription factors in lace plant perforation formation and determine whether they regulate the expression of any PCD-associated genes during perforation formation.

Cytochrome P450s are generally known as key enzymes involved in synthesizing a large variety of secondary plant metabolites such as phytoalexins, lignin, and flavonoids (Butt and Lamb 1981; reviewed by Schuler and Werck-Reichhart 2003). Buchanan-Wollaston (1997) reported the expression of three cytochrome P450 genes in senescencing Brassica napus leaves but not in leaves not undergoing senescence. Xu et al. (2006) also showed that in Petunia inflata, cytochrome P450 was upregulated in the tonoplast during petal senescence. This suggests that they are somehow involved in leaf senescence, but their specific role in senescence is not yet elucidated. In cotton, cytochrome P450s have been shown to regulate systemic cell death (Sun et al. 2014). They are also involved in jasmonate metabolism, 
Table 3

Subclusters and Cellular Processes That the Successfully Annotated Transcript-Derived Fragments (TDFs) Are Involved In

\begin{tabular}{|c|c|c|}
\hline $\begin{array}{l}\text { Subcluster } \\
\text { no. }\end{array}$ & TDFs & Cellular processes \\
\hline 1 & TDF4, TDF9, and TDF10 & $\begin{array}{l}\text { Transcription, transportation of mRNA, translation, organization of the cytoskeleton, } \\
\text { protein folding, remodeling of chromatin, and posttranslational modification of proteins in } \\
\text { several ways including protein activity, localization, interaction, and proteasome-dependent } \\
\text { degradation }\end{array}$ \\
\hline 3 & TDF20, TDF22, and TDF23 & $\begin{array}{l}\text { Hydrolytic activity, plant defense against pathogens, and a ribosomal protein involved in } \\
\text { translation }\end{array}$ \\
\hline 4 & TDF26 and TDF30 & $\begin{array}{l}\text { Histidine biosynthesis, redox reactions, response to ultraviolet light, RNA splicing, biosynthesis } \\
\text { of methionine, and phosphorylation, among other processes }\end{array}$ \\
\hline 5 & $\begin{array}{l}\text { TDF42, TDF43, TDF36, TDF34, } \\
\text { and TDF35 }\end{array}$ & $\begin{array}{l}\text { Hypersensitive response, programmed cell death, protein dephosphorylation thiazole biosyn- } \\
\text { thesis, and response to stresses such as drought and cold }\end{array}$ \\
\hline 9 & TDF81, TDF76, and TDF74 & Calcium binding, component of the ribosomes, and biomass degradation \\
\hline 10 & TDF90 and TDF91 & Jasmonate biosynthesis and recognition of pathogens \\
\hline 11 & $\begin{array}{l}\text { TDF93, TDF97, TDF96, and } \\
\text { TDF98 }\end{array}$ & DNA binding, protein ubiquitination, and response to drought and salt stress \\
\hline 12 & TDF100, TDF101, and TDF104 & $\begin{array}{l}\text { Cell differentiation and several biosynthetic processes including chlorophyll metabolism and } \\
\text { photosynthesis }\end{array}$ \\
\hline 14 & TDF117 and TDF118 & $\begin{array}{l}\text { A protein with serine/threonine kinase activity involved in ATP binding and a component of } \\
\text { nuclear envelope bridging complexes }\end{array}$ \\
\hline 15 & TDF124, TDF126, and TDF130 & $\begin{array}{l}\text { Protein folding, a protein that binds to organellar transcripts in chloroplasts and mitochondria, } \\
\text { and an integral membrane protein }\end{array}$ \\
\hline 16 & $\begin{array}{l}\text { TDF141, TDF145, TDF138, and } \\
\text { TDF143 }\end{array}$ & $\begin{array}{l}\text { Glucose catabolic process, lipid metabolism, a monoterpene synthase, DNA/RNA-binding, } \\
\text { arrangement of microtubules and associated proteins in the cytoskeleton, response to salt, } \\
\text { wounding, and oxidative stresses }\end{array}$ \\
\hline 17 & TDF155 & Terminal oxidase, also thought to be involved during leaf senescence \\
\hline 21 & $\begin{array}{l}\text { TDF197, TDF200, TDF201, } \\
\text { TDF203, and TDF204 }\end{array}$ & $\begin{array}{l}\text { rRNA binding, cell differentiation, transcriptional regulation, DNA binding, regulation } \\
\text { of the cell cycle, and DNA replication }\end{array}$ \\
\hline 22 & TDF206, TDF209, and TDF214 & Carbohydrate metabolism, a transcriptional regulation, and pectin biosynthesis \\
\hline 23 & $\begin{array}{l}\text { TDF219, TDF222, TDF227, and } \\
\text { TDF228 }\end{array}$ & $\begin{array}{l}\text { Ribosomal biogenesis, plant defense against pathogens, RNA binding and splicing, and } \\
\text { importing and transport of light-harvesting complex proteins }\end{array}$ \\
\hline
\end{tabular}

plant defense, and wounding response. As one of the isolated and identified clones, it would be interesting to determine whether the isolated cytochrome P450 monooxygenase is involved in perforation formation by comparing its expression patterns between dying and control cells.

Another EST worthy of further investigation is the putative senescence-associated protein. This clone was isolated 38 times, suggesting that it is a highly expressed protein in window-stage lace plant leaves. The specific name of the gene encoding this protein could not be determined. The homologs in other species are listed only as putative senescence-associated proteins. Senescence is a form of PCD; therefore, this protein is likely somehow involved in PCD. With its apparently high expression in window-stage leaves, it may be involved in the developmentally regulated PCD that leads to perforation formation in lace plant leaves. It would be helpful to discover the exact functional annotation of this protein and also to determine its involvement in lace plant perforation formation.

Some of the genes commonly known to be involved in plant PCD, such as caspase-like enzymes and genes involved in hormonal regulation of PCD (except EIN3-binding F-box protein 1 ), were not identified within the EST database. This is mainly because the technique does not specifically target these genes, is random, and is biased toward highly expressed genes. As a result, most of the ESTs were from generally highly expressed proteins such as the ribosomal and chloroplast proteins. These proteins are not directly related to PCD; however, they will be useful in future research, such as phylogenetic and developmental studies.

The involvement of more PCD-related genes in lace plant PCD can now be studied through direct methods such as realtime PCR, which requires prior knowledge of gene sequences. Through qPCR, we provided evidence that supports the involvement of ubiquitin in lace plant PCD, occurring during perforation formation and leaf senescence (fig. 5). Ubiquitination has been shown to be involved in other plant PCD examples such as leaf senescence (Pinedo et al. 1996; Wang et al. 2014) and hypersensitive response (Marino et al. 2012). During daylily leaf senescence, ubiquitin and ubiquitin conjugates have been shown to increase (Courtney et al. 1994).

To focus more on PCD, separation of dying cells and nondying cells within window-stage leaves before analysis is required. This has recently been achieved through laser-capture microscopy and allows for PCD-specific analysis of gene function (Rantong et al. 2015). The molecular data generated in this study can also be used to study the role of specific genes in other plant developmental processes outside of PCD. This study also makes the lace plant the first species within the Aponogetonaceae family with a considerable amount of gene sequences 
elucidated. Molecular data available on all the other species within this family are limited to the chloroplastic maturase $\mathrm{K}$ (matK) and nuclear DNA (nrITS) loci used in phylogenetic analysis of the Aponogetonaceae family (Les et al. 2005; Chen et al. 2015). The lack of substantial genome sequences from closely related species makes it challenging to successfully annotate new sequences. The large number of unidentified proteins in both the cDNA-AFLP and EST approaches can be accredited to the lack of sequence data and molecular studies in close relatives of the lace plant.

\section{Acknowledgments}

We acknowledge the Botswana International University of Science and Technology (BIUST) and the Botswana Ministry of Education and Skills Development (MoESD) for funding this research. We also acknowledge the National Sciences and Engineering Research Council of Canada (NSERC) for discovery and equipment grants for A. H. L. A. N. Gunawardena. We thank Adrian Dauphinee and Jaime Wertman (Dalhousie University) for critically reviewing this article.

\section{Literature Cited}

Alonso JM, AN Stepanova, R Solano, E Wisman, S Ferrari, FM Ausubel, JR Ecker 2003 Five components of the ethylene-response pathway identified in a screen for weak ethylene-insensitive mutants in Arabidopsis. Proc Natl Acad Sci USA 100:2992-2997.

Bachmair A, F Becker, RV Masterson, J Schell 1990 Perturbation of the ubiquitin system causes leaf curling, vascular tissue alternations and necrotic lesions in a higher plant. EMBO J 9:4543-4549.

Baumeister W, J Walz, F Zühl, E Seemüller 1998 The proteasome: paradigm of a self-compartmentalizing protease. Cell 92:367-380.

Buchanan-Wollaston V 1997 The molecular biology of leaf senescence. J Exp Bot 48:181-199.

Buchanan-Wollaston V, T Page, E Harrison, E Breeze, OL Pyung, GN Hong, JF Lin, et al 2005 Comparative transcriptome analysis reveals significant differences in gene expression and signalling pathways between developmental and dark/starvation-induced senescence in Arabidopsis. Plant J 42:567-585.

Bustin SA, V Benes, T Nolan, MW Pfaffl 2005 Quantitative realtime RT-PCR - a perspective. J Mol Endocrinol 34:597-601.

Butt VS, CJ Lamb 1981 Oxygenases and the metabolism of plant products. Pages 627-665 in EE Conn, ed. Biochemistry of plants: a comprehensive treatise. Vol 7. Academic Press, New York.

Callis J, T Carpenter, CW Sun, RD Vierstra 1995 Structure and evolution of genes encoding polyubiquitin and ubiquitin-like proteins in Arabidopsis thaliana ecotype Columbia. Genetics 139: 921-39.

Chao Q, M Rothenberg, R Solano, G Roman, W Terzaghi, JR Ecker 1997 Activation of the ethylene gas response pathway in Arabidopsis by the nuclear protein ETHYLENE-INSENSITIVE3 and related proteins. Cell 89:1133-1144.

Chen L-Y, GW Grimm, Q-F Wang, SS Renner 2015 A phylogeny and biogeographic analysis for the Cape-Pondweed family Aponogetonaceae (Alismatales). Mol Phylogenet Evol 82:111-117.

Coll NS, A Smidler, M Puigvert, C Popa, M Valls, JL Dangl 2014 The plant metacaspase AtMC1 in pathogen-triggered programmed cell death and aging: functional linkage with autophagy. Cell Death Differ 21:1399-1408.

Courtney SE, CC Rider, AD Stead 1994 Changes in protein ubiquitination and the expression of ubiquitin-encoding transcripts in daylily petals during floral development and senescence. Physiol Plant 91:196-204.

Coux O, K Tanaka, AL Goldberg 1996 Structure and functions of the 20S and 26S proteasomes. Annu Rev Biochem 65:801-847.

Dauphinee AN, AN Gunawardena 2015 An overview of programmed cell death research: from canonical to emerging model species. Pages 1-32 in A Gunawardena, P McCabe, eds. Plant programmed cell death. Springer, Cham, Switzerland.

Dauphinee AN, TS Warner, AHLAN Gunawardena 2014 A comparison of induced and developmental cell death morphologies in lace plant (Aponogeton madagascariensis) leaves. BMC Plant Biol 14:1-13.
Dauphinee AN, H Wright, G Rantong, AHLAN Gunawardena 2012 The involvement of ethylene in programmed cell death and climacteric-like behaviour during the remodelling of lace plant (Aponogeton madagascariensis) leaves. Botany 90:1237-1244.

Elliott A, AHLAN Gunawardena 2010 Calcium inhibition halts developmental programmed cell death in the lace plant, Aponogeton madagascariensis? Botany 88:206-210.

Eulgem T, P Rushton, S Robatzek, I Somssich 2000 The WRKY superfamily of rice transcription factors. Plant Pathol J 5:199-206.

Eulgem T, IE Somssich 2007 Networks of WRKY transcription factors in defense signaling. Curr Opin Plant Biol 10:366-371.

Evans DE 2003 Aerenchyma formation. New Phytol 161:35-49.

Fendrych M, T Van Hautegem, M Van Durme, Y Olvera-Carrillo, M Huysmans, M Karimi, S Lippens, et al 2014 Programmed cell death controlled by ANAC033/SOMBRERO determines root cap organ size in Arabidopsis. Curr Biol 24:931-940.

Gadjev I, JM Stone, TS Gechev 2008 Programmed cell death in plants: new insights into redox regulation and the role of hydrogen peroxide. Int Rev Cell Mol Biol 270:87-144.

Gagne JM, J Smalle, DJ Gingerich, JM Walker, S-D Yoo, S Yanagisawa, RD Vierstra 2004 Arabidopsis EIN3-binding F-box 1 and 2 form ubiquitin-protein ligases that repress ethylene action and promote growth by directing EIN3 degradation. Proc Natl Acad Sci USA 101: 6803-6808.

Giuliani C, G Consonni, G Gavazzi, M Colombo, S Dolfini 2002 Programmed cell death during embryogenesis in maize. Ann Bot 90: 287-292.

Gunawardena AHLAN 2008 Programmed cell death and tissue remodelling in plants. J Exp Bot 59:445-451.

Gunawardena AHLAN, NG Dengler 2006 Alternative modes of leaf dissection in monocotyledons. Bot J Linn Soc 150:25-44.

Gunawardena AHLAN, JS Greenwood, NG Dengler 2004 PCD remodels lace plant leaf shape during development. Plant Cell 16:60-73. 2007 Cell wall degradation and modification during programmed cell death in lace plant, Aponogeton madagascariensis (Aponogetonaceae). Am J Bot 94:1116-1128.

Gunawardena AHLAN, MK Navachandrabala, NG Dengler 2006 Lace plant: a novel system for studying developmental programmed cell death. Pages 157-162 in A Jaime, T da Silva, eds. Floriculture: ornamental and plant biotechnology advances and topical issues. Vol 1. Global Science, Middlesex.

Gunawardena AHLAN, K Sault, P Donnelly, JS Greenwood, NG Dengler 2005 Programmed cell death and leaf morphogenesis in Monstera obliqua (Araceae). Planta 221:607-618.

Guo H, JR Ecker 2003 Plant responses to ethylene gas are mediated by $\mathrm{SCF}^{\mathrm{EBF} 1 / \mathrm{EBF} 2}$-dependent proteolysis of EIN3 transcription factor. Cell 115:667-677.

Hameed A, M Goher, N Iqbal 2013 Drought induced programmed cell death and associated changes in antioxidants, proteases, and lipid peroxidation in wheat leaves. Biol Plant 57:370-374. 
Heise A, B Lippok, C Kirsch, K Hahlbrock 2002 Two immediateearly pathogen-responsive members of the AtCMPG gene family in Arabidopsis thaliana and the W-box-containing elicitor-response element of AtCMPG1. Proc Natl Acad Sci USA 99:9049-9054.

Heyndrickx KS, K Vandepoele 2012 Systematic identification of functional plant modules through the integration of complementary data sources. Plant Physiol 159:884-901.

Hochstrasser M 1996 Ubiquitin-dependent protein degradation. Annu Rev Genet 30:405-439.

Hoeflich KP, M Ikura 2002 Calmodulin in action: diversity in target recognition and activation mechanisms. Cell 108:739-742.

Johnson CS, B Kolevski, DR Smyth 2002 TRANSPARENT TESTA GLABRA2, a trichome and seed coat development gene of Arabidopsis, encodes a WRKY transcription factor. Plant Cell 14:1359-1375.

Kang CH, WY Jung, YH Kang, JY Kim, DG Kim, JC Jeong, DW Baek, et al 2006 AtBAG6, a novel calmodulin-binding protein, induces programmed cell death in yeast and plants. Cell Death Differ 13:84-95.

Kim M, S Lee, K Park, E-J Jeong, C-M Ryu, D Choi, H-S Pai 2006 Comparative microarray analysis of programmed cell death induced by proteasome malfunction and hypersensitive response in plants. Biochem Biophys Res Commun 342:514-521.

Lagacé M, DP Matton 2004 Characterization of a WRKY transcription factor expressed in late torpedo-stage embryos of Solanum chacoense. Planta 219:185-189.

Lam E 2004 Controlled cell death, plant survival and development. Nat Rev Mol Cell Biol 5:305-315.

Lee R, SG Chen 2002 Programmed cell death during rice leaf senescence is nonapoptotic. New Phytol 155:25-32.

Les DH, ML Moody, SWL Jacobs 2005 Phylogeny and systematics of Aponogeton (Aponogetonaceae): the Australian species. Syst Bot 30:503-519.

Lin JF, SH Wu 2004 Molecular events in senescing Arabidopsis leaves. Plant J 39:612-628.

Lord CEN, AN Dauphinee, RL Watts, AHLAN Gunawardena 2013 Unveiling interactions among mitochondria, caspase-like proteases, and the actin cytoskeleton during plant programmed cell death (PCD). PLoS ONE. doi:10.1371/journal.pone.0057110.

Lord CEN, AHLAN Gunawardena 2011 Environmentally induced programmed cell death in leaf protoplasts of Aponogeton madagascariensis. Planta 233:407-421.

Marino D, N Peeters, S Rivas 2012 Ubiquitination during plant immune signaling. Plant Physiol 160:15-27.

Nawkar GM, P Maibam, JH Park, VP Sahi, SY Lee, CH Kang 2013 UV-induced cell death in plants. Int J Mol Sci 14:1608-1628.

Oh M-H, X Wang, X Wu, Y Zhao, SD Clouse, SC Huber 2010 Autophosphorylation of Tyr-610 in the receptor kinase BAK1 plays a role in brassinosteroid signaling and basal defense gene expression. Proc Natl Acad Sci USA 107:17827-17832.

Pandey S, I Somssich 2009 The role of WRKY transcription factors in plant immunity. Plant Physiol 150:1648-1655.

Park S, J-C Moon, YC Park, J-H Kim, DS Kim, CS Jang 2014 Molecular dissection of the response of a rice leucine-rich repeat receptorlike kinase (LRR-RLK) gene to abiotic stresses. J Plant Physiol 171: 1645-1653.

Pinedo ML, SM Goicoechea, L Lamattina, RD Conde 1996 Estimation of ubiquitin and ubiquitin mRNA content in dark senescing wheat leaves. Biol Plant 38:321-328.

Rantong G, R Evans, AHLAN Gunawardena 2015 Lace plant ethylene receptors, AmERS1a and AmERS1c, regulate ethylene-induced programmed cell death during leaf morphogenesis. Plant Mol Biol 89:215-227.

Rantong G, AHLAN Gunawardena 2015 Programmed cell death: genes involved in signaling, regulation, and execution in plants and animals. Botany 210:193-210.
Rogers HJ 2005 Cell death and organ development in plants. Curr Top Dev Biol 71:225-261.

Ross CA, Y Liu, QJ Shen 2007 The WRKY gene family in rice (Oryza sativa). J Integr Plant Biol 49:827.

Saeed AI, V Sharov, J White, J Li, W Liang, N Bhagabati, J Braisted, et al 2003 TM4: a free, open-source system for microarray data management and analysis. Biotechniques 34(2):374-378.

Schuler MA, D Werck-Reichhart 2003 Functional genomics of P450s. Annu Rev Plant Biol 54:629-667.

Snedden WA, H Fromm 2001 Calmodulin as a versatile calcium signal transducer in plants. New Phytol 151:35-66.

Song WY, GL Wang, LL Chen, HS Kim, LY Pi, TE Holsten, J Gardner, et al 1995 A receptor kinase-like protein encoded by the rice disease resistance gene, Xa21. Science 270:1804-1806.

Sun L, L Zhu, L Xu, D Yuan, L Min, X Zhang 2014 Cotton cytochrome P450 CYP82D regulates systemic cell death by modulating the octadecanoid pathway. Nat Commun 5:5372. doi:10.1038 /ncomms6372.

Thomas SG, VE Franklin-Tong 2004 Self-incompatibility triggers programmed cell death in Papaver pollen. Nature 429:305-309.

Vierstra RD 1996 Proteolysis in plants: mechanisms and functions. Plant Mol Biol 32:275-302.

2009 The ubiquitin-26S proteasome system at the nexus of plant biology. Nat Rev Mol Cell Biol 10:385-397.

Vuylsteke M, JD Peleman, MJ van Eijk 2007 AFLP-based transcript profiling (cDNA-AFLP) for genome-wide expression analysis. Nat Protoc 2(6):1399-1413.

Wang H, X Zhu, H Li, J Cui, C Liu, X Chen, W Zhang 2014 Induction of caspase-3-like activity in rice following release of cytochrome-f from the chloroplast and subsequent interaction with the ubiquitinproteasome system. Sci Rep 4:5989.

Wertman J, CE Lord, AN Dauphinee, AHLAN Gunawardena 2012 The pathway of cell dismantling during programmed cell death in lace plant (Aponogeton madagascariensis) leaves. BMC Plant Biol $12: 115$.

Woffenden BJ, TB Freeman, EP Beers 1998 Proteasome inhibitors prevent tracheary element differentiation in zinnia mesophyll cell cultures. Genetics 118:419-430.

Wright H, WG Van Doorn, AHLAN Gunawardena 2009 In vivo study of developmental programmed cell death using the lace plant (Aponogeton madagascariensis; Aponogetonaceae) leaf model system. Am J Bot 96:865-876.

Xie Z, Z-L Zhang, X Zou, J Huang, P Ruas, D Thompson, QJ Shen 2005 Annotations and functional analyses of the rice WRKY gene superfamily reveal positive and negative regulators of abscisic acid signaling in aleurone cells. Plant Physiol 137:176-189.

Xu Y, H Ishida, D Reisen, MR Hanson 2006 Upregulation of a tonoplast-localized cytochrome $\mathrm{P} 450$ during petal senescence in Petunia inflata. BMC Plant Biol 6:1-18.

Xu Y-H, J-W Wang, S Wang, J-Y Wang, X-Y Chen 2004 Characterization of GaWRKY1, a cotton transcription factor that regulates the sesquiterpene synthase gene $(+)-\delta$-cadinene synthase-A. Plant Physiol 135:507-515.

Zhang Z-L, Z Xie, X Zou, J Casaretto, T-HD Ho, QJ Shen 2004 A rice WRKY gene encodes a transcriptional repressor of the gibberellin signaling pathway in aleurone cells. Plant Physiol 134:1500-1513.

Zheng MS, H Takahashi, A Miyazaki, H Hamamoto, J Shah, I Yamaguchi, T Kusano 2004 Up-regulation of Arabidopsis thaliana NHL10 in the hypersensitive response to cucumber mosaic virus infection and in senescing leaves is controlled by signalling pathways that differ in salicylate involvement. Planta 218:740-750.

Zhou X, Y Jiang, D Yu 2011 WRKY22 transcription factor mediates dark-induced leaf senescence in Arabidopsis. Mol Cell 31:303313. 